\title{
Development and Research of China's Current English Education Policy from the Perspective of Linguistic Economics
}

\author{
LiJing, Dai Wei \\ Nanchang Institute of Science \&Technology, Nanchang 330108, China
}

Keywords: International high-level talents, Language economics, English education policy.

\begin{abstract}
After the entry into WTO, the economic globalization has brought opportunities to our country, but also brings challenges, society is increasingly strong demand for the international high-level talents, and English is a very important tool for global people exchanges, it is particularly important to learn English well. The traditional English teaching mode has gradually become out of line with the new society, which cannot keep up with the pace of economic development in the present stage. Therefore, many foreign language researchers in China began to try to analyze the new English education method, and language as human beings is lack of communication tools with its unique economic characteristics, such as investment, income, value, etc.. Based on the perspective of linguistic economics, combined with the relationship between economic variables and linguistic variables, this paper analyzes and explores the current stage English education policy. At the same time, combined with the requirements of high-level talents, this paper puts forward the new English education policy, which can provide a new perspective to cultivate international high-level talents for our country.
\end{abstract}

\section{Introduction}

After the reform and opening up, China has experienced a period of rapid economic development, and the external communication of international technology and culture needs a higher level of English [1-3]. English language education has been paid more and more attention, and linguists and language policy makers have focused on cross disciplinary research, such as social linguistics, psycho linguistics and neural network [4,5]. With the globalization of economy and trade, the exchange between countries is more frequent. In the national level, English helps the country to further open up and get more competition means of high value international projects; in the individual level, English level is considered as a key factor in University study, foreign invested enterprises or joint ventures or further abroad study, these all need to have a high level of English [6-8]. Obviously, English education needs a lot of economic basis, and policy makers often neglect the study of the concept of economics, this paper will combine the views of early language economics research and the use of some important economic framework to analyze and study the current English education policy in China.

\section{China English Education Policy from the Perspective of Language Economics}

In recent years, the research of foreign language education field has experienced one to adapt to the world's policies and planning for the purpose, especially English, it develops a specific English learners [9-11]. Many researchers around the world have begun to question the higher education system in our country, the core position of English education is called the hegemony position; there are a lot of researchers in the study of language economics, they more focus on the scientific language decision-making. The advantages and disadvantages of English education policy in our country from the perspective of linguistic economics can understand the present stage English as a foreign language policy and planning, to find out the potential connection between the theory of language economics and the policy of English education.

Language economics. Language economics is a new discipline that studies language and economy, which can be traced back to the 1960s. The development of information economics Jacob Marschak studied on information economics in 1965 to reveal the information economic nature, he 
thought that language was an indispensable tool in the economic activities of human beings, and it had the same economic characteristics with other resources, namely value, utility, cost and benefit [12]. Therefore, Jacob Marschak found that the optimization of economics and exploration language had a close relationship, the analysis of these four aspects and the discussion of mutual relationship became the important content of language economics. Since then, more and more scholars began to pay close attention to this field, after many years' development, language economics began to enter the mainstream economics research field. In recent years, the English language has proved its strength in the global market economy growth, the language economics in China has also received some attention and development, but also should get more attention in the academic community.

China English education policy and research. In February 2005, Chinese Education Ministry announced on the current university English four and six to carry out major reform, the new approach will start in June 2005 and comprehensive pilot in more than 180 colleges and universities. In order to promote English language ability, Education Ministry developed a new full-time junior middle school English Curriculum Standards and ordinary high school English Curriculum Standards (Experiment), it focused on promoting English curriculum reform in middle school and announced that English classes began the three grade in primary school, and began to accumulate English knowledge from the first grade. At present, there are about 66000000 junior middle school students and about 6000000 senior high school students to learn English [13,14]. In college, students have to learn English or other foreign language for at least two years, and it is clear that English is a member of the foreign language education group, but in the current English policy guidance, Chinese Education Ministry has been defined the long-term and short-term English education goals.

The study of English education policy has aroused great interest of scholars. However, English as a foreign language policy and planning has not yet formed a whole framework, English as a foreign language policy is not very detailed and difficult to meet the globalization. On the contrary, in the case of meeting the needs of local colleges, the higher education research institute can design their own policies and plans in accordance with the requirements of the syllabus, to meet the needs of English as a foreign language policy.

\section{Economic Role of English Education in China}

In China, English education is considered as an important way of learning language. People are willing to invest in language education mainly because of its high economic returns, and English education itself has certain economic characteristics [15]. There is no surprise that people need to consider the value of language when learning a foreign language. As a global language, English is regarded as a kind of property or a form of wealth. Obviously, English has a certain value function.

From the point of individual learners, good English speakers are more likely to sell the products to the English speaking countries, to get a higher value. Or an employee who speaks English, in the same circumstances as all other conditions, may be due to his understanding English and understand some English culture, people can get higher salaries. In addition, a person's English ability is better, and he will be able to show more confidence and pride. On the social level, English is to help a government to further open up a means, it is a valuable resource to realize the country modernization, and it is an important foundation to improve the international competition ability.

Of course, the value of English education must be adjusted and changed according to the value theory of social economics. In the past few decades, especially after the reform and opening up, English has become an essential tool for the development globalization, which involves the political, commercial, financial, military, scientific, mass media and other fields. English has become the key to open the world window or the door to success. In the context of economic globalization, English education is not only a tool, but also has a certain economic benefits.

From the perspective of economics, the utility is the satisfaction of a person's consumption commodity or service. In linguistics, language education is a process of internal and external motivation, linguists usually think that intrinsic motivation refers to the interest of learning, which can promote English learners to learn better; the external motivation generally refers to the money or honor from the external rewards, learners may just want to be able to get a certain economic return to 
engage in certain activities. Linguists believe that the intrinsic motivation of language learning lasts longer, so it is an important prerequisite to achieve long-term success in learning English. Therefore, the same language learners should learn the social properties of language, especially the economic returns; Language policy makers must attach great importance to the coordination of extrinsic motivation and intrinsic motivation, which can arouse the enthusiasm and interest of learning English.

\section{Research on China English Education Policy}

Clearly, some studies have come from the point of economic to explore English education policy. This paper mainly goes through the questionnaire survey to study and analyze the English ability, and then to explore the English education level of economic returns through these studies, but also can be used as a feedback of English education policy. For these considerations, the survey is designed to answer the following questions [16]:

(1) What is the economic return of English language skills?

(2) What is the problem of using English?

(3) What is the attitude of English in the workplace?

(4) What is the economic nature in the adjustment of English education policy?

The purpose of the research is to provide general direct and indirect interests in English language skills to determine the influence of English, and finding the relationship between the good and the quality of the language ability provide some basis for the development of English education policy. The research methods in this research mainly include the research design, research methods and data collection.

Research design. In order to solve the problem, this research chose to investigate the use of English language skills in small and medium enterprises. First of all, the direct result of English education policy implementation realizes the use of English and checks the benefits of English learners, so we need to get into their education and work. Secondly, the choice of small and medium enterprises as the research objects, because they are the perfect combination of personal and social. According to statistics, the company registered in China has $99.6 \%$ small and medium enterprises in 2005, and these small and medium enterprises recruit more than $75 \%$ labor and $70 \%$ foreign trade market. In China, the importance of small and medium enterprises is becoming more and more prominent, they are not only the leading trend of China's integration into the world economy, but also has a far-reaching significance for the development of foreign trade.

Because most of the small and medium enterprises in China, target Corp are not called intensive areas. In order to facilitate and access the object, the researchers chose the location of enterprises in China's East, South, West and north of the four regions, including Zhejiang, Guangdong, Ningxia Hui Autonomous Region and Beijing and other places. In order to save time and avoid long distance travel, sending questionnaire survey mainly use colleagues or friends to help, all of the respondents are in different companies of the four regions. The main topics of the questionnaire are as follows:

Q1: Do you think that English is important in your workplace?

Q2: Do you realize that good English language skills will give you a better chance?

Q3: Do you try to improve your English?

Q4: What are language skills for your work?

Q5: Do you notice any difference between English learning in the school and workplace practice?

Research process. In this study, we use the method of collecting the questionnaire to investigate the advantages of participants in the language skills. All the questionnaires are conducted in China, and survey questionnaire adopts an anonymous way in order to encourage the participants to answer questions honestly. Throughout the study, a total of hundreds of electronic questionnaires were sent out in the four areas of the survey, we should inform the purpose of the questionnaire before the participants were informed, to ensure that data was only used to investigate, it will not appear other negative effects. In the survey, we received a total of 75 copies completed questionnaires, and then through the office excel 2003 data processing and analysis. 


\section{Results and Analysis}

Through the survey, we have obtained a series of the economic features of English language skills, economic returns and other data information. According to different background information to distinguish and research analysis, this paper is mainly four aspects of the company nature, occupation, education background and the use of purpose to carry out analysis and discussion.

(1) Company nature

According to survey information statistics being investigated company nature, company nature and proportion are shown in Table 1.

Table 1 . The nature and proportion of being investigated company

\begin{tabular}{|c|c|c|c|c|c|}
\hline State-owned & Collective & Private & Foreign enterprise & Joint venture & No \\
\hline 25 & 18 & 14 & 8 & 9 & 1 \\
\hline $33.3 \%$ & $24 \%$ & $18.7 \%$ & $10.7 \%$ & $12 \%$ & $1.3 \%$ \\
\hline
\end{tabular}

In Table 1, it can be seen that the state owned enterprises occupy the largest part of the $33.3 \%$ in all companies, followed by the collective and private enterprises that respectively occupy $24 \%$ and 18.7\%. 8 foreign companies should be more frequent use of English, so they should be more requirements for the English level, the industry and the degree of proficiency in English will get different salary treatment in different nature enterprise. This paper mainly studies the relationship between pay and the ability of English language, in order to have comprehensive analysis results of English education policy, this paper tries to cover more types of companies.

(2) Personal information

For personal information, people main collect professional, educational background data and other data. According to the different background, the data information classifies the statistics. The professional and its proportion of respondents are shown in Table 2.

Table 2. The professional and its proportion of respondents

\begin{tabular}{|c|c|c|c|c|c|}
\hline Business & Technology & Foreign languages & Administration & Other & No \\
\hline 19 & 24 & 16 & 13 & 2 & 1 \\
\hline $25.3 \%$ & $33.3 \%$ & $21.3 \%$ & $17.3 \%$ & $2.7 \%$ & $1.3 \%$ \\
\hline
\end{tabular}

In Table 2, business professionals include international trade, accounting, finance and economics; engineering includes computer control, network engineering, mechanical and other engineering majors; Foreign languages includes English, Japanese, French and Chinese, etc.; management includes business administration, human resources, marketing and other professional. This paper contains all kinds of professional in college, which is more persuasive for the analysis of English education policy.

(3) Education background

In most companies, staff educations are directly linked to wages. In order to reduce the impact of external factors on the analysis of English education policy analysis and according to the survey conducted by the degree of education, the respondents' education level information is shown in Table 3.

Table 3. The education background of respondents

\begin{tabular}{|c|c|c|c|c|}
\hline Doctor & Master & Bachelor degree & Other & No \\
\hline 0 & 20 & 45 & 10 & 0 \\
\hline 0 & $26.7 \%$ & $60 \%$ & $13.3 \%$ & 0 \\
\hline
\end{tabular}

As shown in Table 3, the majority of the respondents are bachelor degree, in which $26.7 \%$ respondents have master's degree. In the survey, there is no high degree of doctoral students, because the general small and medium enterprises no need to recruit doctoral students because of their size and research direction and other reasons. For these respondents, there is no extra-curricular English language education experience.

(4) The use of purpose

Based on the purpose of use or the use of the English language to analyze the education, the analysis of the current research of English education in China is relatively high. This paper according 
to the work need to develop the work including the discussion and communication with customers, and customer communication, and communication with the customers, and the communication with customers, and the exchange and the use of English, etc.. English use of the target data is shown in table 4.

Table 4. The purpose of using English respondents

\begin{tabular}{|c|c|c|c|c|}
\hline $\begin{array}{c}\text { Discuss and } \\
\text { communicate with } \\
\text { customers }\end{array}$ & $\begin{array}{c}\text { Communicate with customers and } \\
\text { communicate with colleagues }\end{array}$ & $\begin{array}{c}\text { Daily } \\
\text { greetings }\end{array}$ & $\begin{array}{c}\text { Seldom use } \\
\text { English }\end{array}$ & No \\
\hline 21 & 16 & 28 & 10 & 0 \\
\hline $28 \%$ & $21.3 \%$ & $37.38 \%$ & $13.38 \%$ & 0 \\
\hline
\end{tabular}

As shown in Table 4, nearly three people participated in this survey questionnaire said that they need to use English to communicate, appease and handle claims with customers; $21.3 \%$ participants said not only need to English communicate with customers, colleagues or peers exchange information also need to use English, this may happen in the foreign company. The results can be seen that English is not only as a written language, but also is a verbal communication tool, more important is that English is a bridge between different cultures and is a necessary part of the international business community.

Combined with above four table data, they can be seen that in the foreign company or often face to face with foreign exchange companies, those who have a high English proficiency generally have a greater advantage. English can not only be regarded as a powerful tool to gain more information, but also English skills can improve the professional ability.

\section{Summary}

This paper mainly focuses on the analysis of four questions associated with English language skills, the results show that the importance of English language skills is obvious, and the survey results have a certain guiding role in policy. In the near future, the form of economic globalization will become more apparent, the market language decision-making will make English learning more practical and recognition. Based on the cost benefit analysis of the language economics, combined with the cost factor of language policy, this paper goes through empirical research and analysis of the benefits of English language skills, the results show that the main income of strong English language ability comes from the process of the conversion economic benefits rather than market efficiency. From different working conditions, the use of English survey results can reflect that the current English education policies also need to improve, the level of English proficiency in different social areas need to be improved more reasonable and effective English education policy, which can promote the development of more international high-level personnel.

\section{References}

[1] S.A. Huang, J. Su, W.G. Zhang. The meaning of language industry and the development strategy of Chinese language industry. Economic aspect, 2014(5): 24-28.

[2] J. Su, S.A. Huang, W.G. Zhang. Language economics and its subject positioning.. Jianghan forum, 2013(6): 21-25.

[3] S.A. Huang, J. Su, W.G. Zhang. Language economics and its development in China. Economic dynamics, 2013(3): 41-46.

[4] W.G. Zhang, G.H. Liu. Study on China language economics. Language teaching and research, 2013(6) :102-109.

[5] Y.X. Guo. Research on the protection of language rights and minority language rights. Minzu University of China, 2013: 1-12. 
[6] J. Su. Language evolution and language protection: analysis framework of the language economics. Shandong University, 2013: 7-18.

[7] Z.S. Mo. Research on business English education under the perspective of language economics. Foreign field, 2013(2): 65-72.

[8] S.K Wang, L.X. Dai. Language resources and language theory research. Journal of Shenyang Institute of Engineering, 2013(3): 381-383.

[9] S. Wei. Language economics. Dongyue Forum, 2013(11): 5-29.

[10] C.C. Lian. The higher vocational English education from the perspective of language economics. Shaanxi Education (Higher Education), 2014(11): 37-38.

[11] Y.H. Wu, J.X. Zhang. Economic linguistics: a new frontier of science and pursuit. Guizhou social science, 2013(8): 83-86.

[12] D.F. Zhang, B. Guan. A comparative study of foreign language economics and language economics. Business studies, 2013(11): 173-179.

[13] S.A. Huang, J. Su. A few basic propositions of language economics. Academic Journal, 2013(9): 82-87.

[14] X. Zeng. Research on the language economic value of concise business English [J]. market modernization, 2014(35): 37-39.

[15] Z.S. Mo, X.Y. Zhang, Y. Zhang. Business English research based on language economics. Journal of Hunan University, 2013(4): 102-106.

[16] B. Fang. The university English teaching and its Enlightenment from the perspective of human capital investment theory. Academic forum, 2013(1): 224-227. 